(Preimplantation Genetic Testing -PGT) là sự kết hợp giữa kỹ thuật thụ tinh trong ống nghiệm (In vitro fertilization - IVF) với kỹ thuật chẩn đoán di truyền; qua đó giúp lựa chọn các phôi không mang gen bệnh để chuyển vào tử cung người mẹ, giúp người mẹ mang thai không bị bệnh và sinh con khỏe manh.

Hiện nay, có hai phương pháp chính để chẩn đoán bệnh là chẩn đoán trực tiếp và chẩn đoán gián tiếp. Với khoảng hơn 300 đột biến gen HBB đã được xác định, các phương pháp xác định trực tiểp sẽ gặp khó khăn trong quá trình tối ưu hóa phản ứng để xác định từng đột biến $[4,5]$. Đăc biệt khi thực hiện trên sản phẩm WGA từ mẫu sinh thiết phôi nhằm phục vụ quy trình PGT-M, hiện tượng $A D O$ và ngoại nhiễm có dẫn tới các kết quả sai, tỷ lệ này lên tới $30 \%$ [2]. Áp dụng bộ chỉ thị gồm các STR có tính đa hình cao và liên kết chặt chẽ với gen $\mathrm{HBB}$, qua đó giúp xác định được sự di truyền của tổn thương gen, đồng thời kiểm soát được ngoại nhiễm và hiện tượng $\mathrm{ADO}$ là rất quan trọng trong quy trình PGT-M $\beta$-thalassemia. Theo Hiệp hội hỗ trợ sinh sản và phôi học Châu Âu (ESHRE) 2020 khuyến cáo, việc phối hợp sử dụng kĩ thuật chẩn đoán trực tiếp và gián tiếp là cần thiết trong quy trình PGT-M để tăng độ chính xác của chẩn đoán [2].

Nghiên cứu của chúng tôi báo cáo 1 trường hợp gia đình thực hiện kĩ thuật PGT-M với sự kết hợp của phương pháp trực tiếp và gián tiếp; qua đó phát hiện được hiện tượng ADO khiến chẩn đoán sai nếu chỉ đơn độc dựa vào kết quả trực tiếp, thậm chí có thể dẫn tới việc không chuyển đúng phôi có kiểu gen bình thường cho người mẹ. Kết quả của nghiên cứu đã củng cố vững chắc vai trò quan trọng của phương pháp di truyền liên kết sử dụng các STR liên kết với gen HBB trong PGT-M bệnh $\beta$-thalassemia.

\section{KẾT LUÂ̂N}

Hiện tượng $A D O$ gây chẩn đoán sai trong PGT. Do đó, việc áp dụng đồng thời phương pháp trực tiếp và̀ gián tiếp trong PGT-M bệnh $\beta$ thalassemia là rất cấp thiết để khắc phục $A D O$ và cải thiện độ chính xác của PGT.

\section{TÀI LIÊU THAM KHẢO}

1. G. L. Harton, M. De Rycke và cs. (2011), "ESHRE PGD consortium best practice guidelines for amplification-based PGD", Hum Reprod. 26(1), tr. 33-40.

2. ESHRE PGT-M Working Group, Filipa Carvalho và CS. (2020), "ESHRE PGT Consortium good practice recommendations for the detection of monogenic disorders". 2020(3), tr. hoaa018.

3. Douglas $\mathbf{R}$ Higgs, James Douglas Engel và George Stamatoyannopoulos (2012), "Thalassaemia", The lancet. 379(9813), tr. 373-383.

4. Raffaella Origa (2018), "Beta-thalassemia",

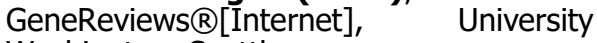
Washington, Seattle.

5. Shahid Raza, Sahrish Farooqi và cs. (2016), "Beta thalassemia: prevalence, risk and challenges". 2(1), tr. 5-7.

6. DJ Weatherall và John $B \% J$ Bulletin of the World Health Organization Clegg (2001), "Inherited haemoglobin disorders: an increasing global health problem". 79, tr. 704-712.

\title{
ĐÁNH GIÁ MỨC Độ THUÂ̂N LỢI CỦA PHẪU THUÂT RĂNG KHÔN BẰNG PHƯƠNG PHÁP AN THẦN ĐÍCH PROPOFOL (TCI)
}

\author{
Mai Đức Hạnh ${ }^{1}$, Nguyễn Quang Bình ${ }^{2}$, Vũ Doãn Tú ${ }^{2}$, \\ Trần Đắc Tiệp ${ }^{1}$, Lê Tịnh ${ }^{\mathbf{1}}$, Nguyễn Trung Kiên ${ }^{1}$
}

\section{TÓM TẮT}

Mục tiêu: Đánh giá mức độ thuận lợi của phẫu thuật răng khôn bằng phương pháp targèt controlled infusion (TCI) propofol. Đối tượng và Phương pháp: thử nghiệm lâm sàng, ngấu nhiên có đối chứng. Tiến hành trên 60 bệnh nhân nhổ răng khôn,

\footnotetext{
${ }^{1}$ Bệnh viện Quân y 103

²Bệnh viện Răng hàm mặt Trung ương Chịu trách nhiệm chính: Mai Đức Hạnh Email: maiduchanh5992@gmail.com Ngày nhận bài: 26.10.2020 Ngày phản biện khoa học: 30.11.2020 Ngày duyệt bài: 10.12.2020
}

tuổi 16 - 50, ASA I, II. Nhóm $1(n=30)$ : Gây mê toàn thân để tiến hành phẫu thuật tại khoa Gây mê, Bệnh viện Răng Hàm Mặt Trung ương Hà Nội. Nhóm 2 ( $\mathrm{n}=$ 30): Sử dụng nồng độ propofol an thần theo đích tại não $(\mathrm{Ce})$ bằng propofol $10 \%$. Phương pháp đánh giá: đă̆c điểm chung, mức độ khó phẫu thự̣̂t răng khôn hàm dưới theo pedersen, thời gian phấu thuật, mức độ cử động của bệnh nhân theo Ellis, mức độ an thẫn $\mathrm{OAA} / \mathrm{S}$, tổng liều lidocain, mức độ hài lòng của phẫu thuật viên theo VAS. Kết quả: Nhóm 2 có tuổi trung bình là $27,17 \pm 9,27$ năm tương đương nhóm 1 là $27,33 \pm 8,62$ năm ( $p>0,05)$; cân nặng trung bình nhóm 2 là $56,67 \pm 10,37 \mathrm{~kg}$ tương đướng nhóm 1 là 55,46 $\pm 10,15 \mathrm{~kg}(\mathrm{p}>0,05)$; tổng liều thuốc tê lidocain là $205.9 \pm 24.95 \mathrm{mg}$ tương đương nhóm 1 là $191.1 \pm$ $31.14 \mathrm{mg}(\mathrm{p}>0,05)$. Nhóm 2 có tổng liều propofol 
trung bình là $107.27 \pm 13.86$ mg thấp hơn nhóm 1 có tổng liều propofol trung bình là $278.5 \pm 73.31$ $(p<0,05)$, mức an thần nhóm 1 cho phép phẫu thuật ( $5>\mathrm{OAA} / \mathrm{S} \geq 3), 2$ nhóm có mức độ khó của răng như nhau thời gian phẫu thuật của 2 nhóm tương đương nhau $(p>0,05)$, Số bệnh nhân cử động khác nhau không có ý nghĩa $(p>0,05)$, Mức độ rất hài lòng của PTV ở nhóm 2 cao hơn nhóm $1(p<0,05)$. Kết luận: sử dụng phương pháp an thần đích propofol trong phẫu thuật răng khôn cho hiệu quả an thân tốt, tạo thuận lợi cho phẫu thuật viên.

Tư khóa: Target controlled infusion, propofol, phẫu thuật nhổ răng khôn.

\section{SUMMARY}

\section{EVALUATION THE CONVENIENCE OF TARGET CONTROLLED INFUSION (TCI) USING PROPOFOL FOR WISDOM TEETH EXTRACTION PROCEDURE}

Objective: Evaluation the convenience of target controlled infusion (TCI) using propofol for wisdom teeth extraction procedure. Objective Summary: To evaluate the advantage of third molar surgery using the target controlled infusion (TCI) by propofol method. Subjects and Methods: Clinical, randomized controlled trial. Conducted on 60 patients with third molar extraction, aged 16-50, ASA I, II. Group $1(\mathrm{n}=$ 30): General anesthesia to perform surgery at the Anesthesia Department, Hanoi Central Dental Hospital. Group $2(n=30)$ : Using the target brain sedative propofol concentration (Ce) by $10 \%$ propofol. Assessment methods: general characteristics, degree of difficulty in lower third molar surgery according to pedersen, surgery time, patient movement level according to Ellis, level of sedation OAA / S, total lidocaine dose, degree Surgeons' satisfaction according to VAS. Results: Group 2 has an average age of $27.17 \pm 9.27$ years, equivalent to group 1 is $27.33 \pm 8.62$ years ( $p>0.05)$; The average weight of group 2 was $56.67 \pm 10.37 \mathrm{~kg}$, equivalent to group 1 was $55.46 \pm 10.15 \mathrm{~kg}$ ( $p>0.05)$; total dose of lidocaine anesthetic was $205.9 \pm 24.95 \mathrm{mg}$ equivalent to group 1 was $191.1 \pm 31.14 \mathrm{mg}(\mathrm{p}>0.05)$. Group 2 had a total mean propofol of $107.27 \pm 13.86 \mathrm{mg}$, which was lower than group 1 with mean total propofol of $278.5 \pm 73.31$ ( $\mathrm{p}<0.05)$, and group 1 sedation levels allow ( $5>\mathrm{OAA} / \mathrm{S} \geq 3), 2$ group has a way of hard Falence as the way of the time of the 2 group is the same ( $p>0.05)$, No means ( $p>0.05)$, The level of PTV very satisfied in group 2 is higher than group 1 ( $p<0.05)$. Conclusion: Using propofol TCI for third molar surgery has good sedative effect, facilitating surgeons..

Keywords: target controlled infusion, propofol, wisdom teeth extraction procedure.

\section{I. ĐĂT VẤN ĐỀ}

Đặt vấn đề: Phẫu thuật nhổ răng khôn (răng số 8) là phẫu thuật thường gặp trong nha khoa. Lí do bệnh nhân đến phẫu thuật chủ yếu là: do sưng, đau $87,50 \%$ và tái phát nhiều lần $96,43 \%$ [1]. Mức độ khó của phẫu thuật là: khó ít
$(9,09 \%)$; khó trung bình $77,27 \%$; rất khó 13,64\% [2]. Các cản trở răng mọc thường do kẹt răng số 7 kề bên $25,52 \%$, do xương hàm dưới 23,44\%[1]. Phương pháp vô cảm thường dùng là gây tê tại chỗ tuy nhiên phương pháp này có thể làm cho bệnh nhân sợ đau, lo lắng, khó chịu ít nhiều ảnh hưởng đến quá trình phẫu thuật. Với những phẫu thuật răng khôn khó, phức tạp, bệnh nhân được gây mê nội khí quản tạo thuâân lợi cho phẫu thuật viên trong quá trình phầu thuật [3]. Phương pháp TCI (an thần nồng độ đích) là kết hợp an thần trong vô cảm tại chỗ nhằm làm cho bệnh nhân thư giãn, giảm lo lắng, tạo điều kiện thuận lợi cho phẫu thuật viên khi thao tác, rút ngắn thời gian phẫu thuật. Vì vậy chúng tôi đã tiến hành nghiên cứu: Đánh giá mức độ thuận lợi của phẫu thuật răng khôn bằng phương pháp an thần đích propofol (TCI).

\section{II. ĐỐI TƯỢNG VÀ PHƯƠNG PHÁP NGHIÊN CỨU}

2.1. Đối tượng nghiên cứu: 60 bệnh nhân nhổ răng khôn, tuổi 16 - 50, ASA I, II. Nhóm 1 $(n=30)$ : Gây mê toàn thân để tiến hành phẫu thuật tại khoa Gây mê, Bệnh viện Răng Hàm Mặt Trung ương Hà Nội. Nhóm $2(n=30)$ : Sử dụng nồng độ propofol an thần theo đích tại não ( $\mathrm{Ce}$ ) bằng propofol $10 \%$.

\subsection{Phương pháp nghiên cứu}

2.2.1. Thiết kế nghiên cứu: thử nghiệm lâm sàng, ngẫu nhiên có đối chứng: Nhóm 2 $(n=30)$ : nhóm nghiên cứu, sử dụng TCI propofol. Nhóm 1 ( $\mathrm{n}=30)$ : nhóm chứng, gây mê nội khí quản.

\subsubsection{Phương pháp tiến hành}

- Chuẩn bị bệnh nhân, dụng cụ, phương tiện: Khám và giải thích cho người bệnh về nguyên tắc, phương pháp dùng an thần TCI; chuẩn bị các phương tiện và thuốc hồi sức cấp cứu hố hấp, tuần hoàn.. .; máy Monitoring điện tim theo dõi: tần số tim, huyết áp của cả hai nhóm; thuốc nghiên cứu: propofol $1 \%$, lidocain $2 \%$ có epinephrine 1/100 000; bơm tiêm điện TCI (Perfusor fm B/Braun ) của Đức.

\section{- Phương pháp vô cảm:}

Nhóm 1: gây mê nội khí quản; khởi mê: tiêm tĩnh mạch Propofol 2,5 mg/kg + Fentanyl 4 $\mathrm{mcg} / \mathrm{kg}+$ Esmeron $0,6 \mathrm{mg} / \mathrm{kg}$ và đặt nội khí quản sau 1 phút; duy trì mê: duy trì TCI propofol $10 \%$ liêu $2,5 \mathrm{mcg} / \mathrm{ml}$; kết thúc mê: tắt thuốc mê khi kết thúc phẫu thuật.

Nhóm 2: an thần đích băng propofol; đặt chế độ TCI propofol theo cân nặng, tùy chinh theo đáp ứng của bệnh nhân. Trong phẫu thuật duy trì từ $0,8 \mathrm{mcg} / \mathrm{ml}$ đến $1,2 \mathrm{mcg} / \mathrm{ml}$; cả hai 
nhóm kết hợp gây tê tại chỗ bằng lidocain $2 \%$ có epinephrin $1 / 100.000$ liều đầu $2-4 \mathrm{mg} / \mathrm{kg}$, sau 5 phút tiến hành phẫu thuật; trong quá trình phẫu thuật bệnh nhân đau có thể thêm lidocain tùy theo đáp ứng của bệnh nhân (tổng liều lidocain $<6 \mathrm{mg} / \mathrm{kg}$ ).

- Phương pháp đánh giá: Tất cả các bệnh nhân phẫu thuật nhổ răng khôn đều được tiến hành do một phẫu thuật viên có kinh nghiệm; đánh giá mức độ an thần của bệnh nhân trong phẫu thuật theo $\mathrm{OAA} / \mathrm{S}$; đánh giá các cử động bất thường của bệnh nhân trong phẫu thuẫ̂t; tổng liều lidocain sử dụng; mức độ khó của phẫu thuật răng khôn hàm dưới theo pedersen; thời gian phẫu thuật: tính từ lúc tiêm tê đến khi kết thúc khâu đóng niêm mạc; đánh giá mức độ hài lòng của phẫu thuât viên theo VAS: hỏi sau phẫu thuật (điểm từ 0 đến 10; 0 - 2: không hài lòng; 2 - 4: hài lòng ít; 4 - 6: hài lòng vừa; 6 - 8: hài lòng nhiều; 8 - 10: rất hài lòng).

\section{KẾT QUẢ NGHIÊN CỨU}

3.1. Đặc điểm chung của bệnh nhân. Nhóm 2 có tuổi trung bình là 27,17 \pm 9,27 năm tương đương nhóm 1 là 27,33 $\pm 8,62$ năm ( $p>0,05)$; cân nặng trung bình nhóm 2 là 56,67 $\pm 10,37 \mathrm{~kg}$ tương đương nhóm 1 là $55,46 \pm$ $10,15 \mathrm{~kg}(\mathrm{p}>0,05)$; tổng liều thuốc tê lidocain là $205.9 \pm 24.95 \mathrm{mg}$ tương đương nhóm 1 là 191.1 $\pm 31.14 \mathrm{mg}(\mathrm{p}>0,05)$. Nhóm 2 có tổng liều propofol trung bình là $107.27 \pm 13.86 \mathrm{mg}$ thấp hơn nhóm 1 có tổng liều propofol trung bình là $278.5 \pm 73.31(p<0,05)$

3.2. Đánh giá mức độ thuận lợi của phẫu thuật ở hai nhóm

3.2.1. Đánh giá mức độ an thân của bệnh nhân trong phẫu thuật theo $O A A / S$

Bảng 1. Mức độ an thần của bệnh nhân trong phẫu thuật theo $O A A / S$

\begin{tabular}{|c|c|c|c|}
\hline $\begin{array}{c}\text { Thời } \\
\text { điểm }\end{array}$ & $\begin{array}{c}\text { Nhóm 1 } \\
(\mathbf{n = 3 0 )} \\
\mathbf{x} \pm \mathbf{~ S D}\end{array}$ & $\begin{array}{c}\text { Nhóm 2 } \\
(\mathbf{n = 3 0 )}\end{array}$ & $\mathbf{p}$ \\
\hline $\mathbf{T}_{\mathbf{0}}$ & $5 \pm 0$ & $5 \pm 0$ & $>0,05$ \\
\hline $\mathbf{T}_{\mathbf{1}}$ & $1 \pm 0$ & $3,96 \pm 0,18$ & $<0,05$ \\
\hline $\mathbf{T}_{\mathbf{2}}$ & $1 \pm 0$ & $3,63 \pm 0,61$ & $<0,05$ \\
\hline $\mathbf{T}_{\mathbf{3}}$ & $1 \pm 0$ & $3,8 \pm 0,55$ & $<0,05$ \\
\hline $\mathbf{T}_{\mathbf{4}}$ & $1 \pm 0$ & $3,66 \pm 0,6$ & $<0,05$ \\
\hline $\mathbf{T}_{\mathbf{5}}$ & $1 \pm 0$ & $3,7 \pm 0,46$ & $<0,05$ \\
\hline $\mathbf{T}_{\mathbf{x}}$ & $5 \pm 0$ & $5 \pm 0$ & $<0,05$ \\
\hline
\end{tabular}

Nhận xét: Tại thời điểm trước phầu thuật 5 phút To mức độ an thần của 2 nhóm tương đương nhau $(p>0,05)$. Từ thời điểm phẫu thuật $T_{1}$ đến $T_{5}$ nhóm 1 gây mê hoàn toàn, nhóm 2 an thần ( 5 $>\mathrm{OAA} / \mathrm{S}>3)$ cho phép phẫu thuật. $(\mathrm{p}<0,05)$. Tại thời điểm xuất khoa $\mathrm{T}_{x}$ mức độ an thần $(\mathrm{OAA} / \mathrm{S}=$ $5)$ hai nhóm hoàn toàn tỉnh táo $(p>0,05)$.

\subsubsection{Số bệnh nhân cử động trong phẫu} thuât

Bảng 2. Số lần cử động cản trở phẫu thuật

\begin{tabular}{|c|c|c|c|c|c|}
\hline \multirow{2}{*}{$\begin{array}{l}\text { Mức độ cử } \\
\text { động của } \\
\text { bệnh nhân }\end{array}$} & \multicolumn{2}{|c|}{$\begin{array}{l}\text { Nhóm 1 } \\
(\mathrm{n}=30)\end{array}$} & \multicolumn{2}{|c|}{$\begin{array}{l}\text { Nhóm } 2 \\
(n=30)\end{array}$} & \multirow[t]{2}{*}{ p } \\
\hline & $n$ & $(\%)$ & $n$ & (\%) & \\
\hline $\begin{array}{l}\text { Không cử } \\
\text { đông }\end{array}$ & 30 & 100 & 29 & 96,67 & $>$ \\
\hline Cử động & 0 & 0 & 1 & 3,33 & \\
\hline
\end{tabular}

Nhận xét: Mức độ cử động nhóm 2 cao hơn (3,33\%) nhóm $1(0 \%)$ không có ý nghĩa thống kê $(p>0,05)$.

\subsubsection{Mức độ khó của phẫu thuâtt răng khôn hàm dưới theo Pedersen} Bảng 3. Mức độ khó của phấu thuật răng khôn hàm dưới theo Pedersen

\begin{tabular}{|c|c|c|c|c|c|c|c|c|c|}
\hline \multirow{3}{*}{$\begin{array}{l}\text { Mức độ khó } \\
\text { phẫu thuật }\end{array}$} & \multicolumn{4}{|c|}{ Nhóm 1 ( $(\mathrm{n}=30)$} & \multicolumn{4}{|c|}{ Nhóm $2(n=30)$} & \multirow{3}{*}{$\mathrm{p}$} \\
\hline & \multicolumn{2}{|c|}{ Răng 38} & \multicolumn{2}{|c|}{ Răng 48} & \multicolumn{2}{|c|}{ Răng 38} & \multicolumn{2}{|c|}{ Răng 48} & \\
\hline & $\mathbf{n}$ & $(\%)$ & $\mathbf{n}$ & $(\%)$ & $\mathbf{n}$ & (\%) & $\mathbf{n}$ & (\%) & \\
\hline Khó ít & 2 & 6,67 & 3 & 10 & 3 & 10 & 4 & 13,33 & \\
\hline Khó vừa & 24 & 79,99 & 24 & 79,99 & 23 & 76,67 & 24 & 79,99 & 0,05 \\
\hline Rất khó & 4 & 13,33 & 3 & 10 & 4 & 13,33 & 2 & 6,67 & $>0,05$ \\
\hline
\end{tabular}

Nhận xét: Mức độ khó ở hai nhóm khác nhau không có ý nghĩa thống kê ( $p>0,05)$.

\subsubsection{Thời gian tiến hành phẫu thuật ở hai nhóm}

Bảng 4. Thời gian tiến hành phẫu thuật

\begin{tabular}{|c|c|c|}
\hline Thời gian GM/AT và PT (phút) & Nhóm $\mathbf{1}(\mathbf{n}=\mathbf{3 0})$ & Nhóm $\mathbf{2}(\mathbf{n}=\mathbf{3 0})$ \\
\hline $\mathbf{x} \pm$ SD & $38,96 \pm 6,75$ & $36,66 \pm 4,17$ \\
\hline $\mathbf{P}$ & \multicolumn{2}{|c|}{$<0,05$} \\
\hline
\end{tabular}

Nhận xét: Thời gian phẫu thuật ở hai nhóm tương đương nhau $(p>0,05)$.

3.2.5. Mức độ hài lòng của phấu thuật viên

Bảng 5. Đánh giá mức độ hài lòng của phẫu thuật viên

\begin{tabular}{|c|c|c|c|c|c|}
\hline \multirow{2}{*}{ Mức độ hài lòng } & \multicolumn{2}{|c|}{ Nhóm 1 $(\mathbf{n}=\mathbf{3 0})$} & Nhóm 2 $(\mathbf{n}=\mathbf{3 0})$ & \multirow{2}{*}{ p } \\
\cline { 2 - 5 } Không hài lòng & $\mathbf{n}$ & $\mathbf{( \% )}$ & $\mathbf{n}$ & $\mathbf{( \% )}$ & \\
\hline
\end{tabular}




\begin{tabular}{|c|c|c|c|c|c|}
\hline Hài lòng & 28 & 93,30 & 20 & 66,67 & \multirow{2}{*}{$<0,05$} \\
\hline Rất hài lòng & 2 & 6,70 & 10 & 33,33 & \\
\hline
\end{tabular}
$(\mathrm{p}<0,05)$.

\section{BÀN LUÂN}

Mức độ thuận lợi của phẫu thuật dựa trên các yếu tố đó là mức độ an thần, số lần bệnh nhân cử động cản trở phẫu thuật, độ khó của phẫu thuật, thời gian làm phẫu thuật và mức độ hài lòng của phẩu thuật viên

4.1. Mức độ an thân trong phẫu thuật của bệnh nhân theo OAA/S. Kết quả ở bảng 1 cho thấy tại thời điểm trước phẫu thuật $\mathrm{T}_{0}$ và chuẩn bị xuất khoa $T_{x}$ bệnh nhân giữa 2 nhóm tỉnh táo $(O A A / S=5)(p>0,05)$, thời gian phẫu thuật từ $T_{1}$ đến $T_{5}$ nhóm 1 mê hoàn toàn, nhóm $2(5>O A A / S \geq 3)(p<0,05)$ mức an thần đủ cho phẫu thuật.

Nguyễn Quang Bình (2018) nghiên cứu TCI bằng propofol ở bệnh nhân tháo nẹp vít xương gò má có mức độ an thần theo OAA/S ở các thời điểm $T_{0}$ và $T_{x}(O A A / S=5)$ tại các thời điểm phẫu thuật $T_{1}$ đênn $T_{x}(5>O A A / S \geq 3)$. Không có bênh nhân nào an thần quá sâu $(\mathrm{OAA} / \mathrm{S} \leq 2)$ [4]. Kết quả của chúng tôi phù hợp với kết quả của tác giả.

4.2. Số bệnh nhân cử động trong phẫu thuật. Kết quả bảng 2 cho thấy số bệnh nhân không cử động trong phẫu thuật với mức tốt ở nhóm TCI $(96,67 \%)$ thấp hơn không có ý nghĩa $(p<0,05)$ so với nhóm GM (100\%). Như vậy, ở nhóm TCI tác dụng an thần của propofol giúp bệnh nhân hợp tác tốt, thoải mái, dễ dàng chấp nhận và phẫu thuật được thuận lợi gần tương tự nhóm GM. Tuy nhiên, khi gây mể toàn thân các tai biến do hô hấp và tuần hoàn luôn được đặt ra. Như vậy, với phẫu thuật vừa như nhổ rẳng số 8 chỉ cần sử dụng phương pháp TCI propofol kết hợp với gây tể tại chỗ là có thể tiến hành phẫu thuật tốt và an toàn.

Nguyễn Quang Bình (2018) nghiên cứu TCI bằng propofol ở bênh nhân tháo nẹp vít xương gò má có 1 bệnh nhân có cử động trong mổ [4]. Do đó ết quả của chúng tôi phù hợp với kết quả nghiên cứu của tác giả.

4.3. Mức độ khó phẫu thuật. Kết quả ở bảng 3 cho thấy mức độ khó của phẫu thuật giữa 2 nhóm là tương đương nhau khác biệt không có ý nghĩa thống kê $(p>0,05)$, ở những bệnh nhân được phân loại mức độ dễ và vừa, mức độ không quá khó để thực hiện và vị trí răng thường dễ lấy, phương pháp TCI propofol kết hợp với gây tê tại chỗ là phù hợp với loại phẫu thuật dễ và vừa, nó có thể thay thế phương pháp nội khí quản mà chúng ta áp dụng thường qui là hiệu quả, giảm tai biến, phiên nạn và giảm chi phí, dễ thực hiện.

4.4. Thời gian tiến hành phẫu thuật. Trong nghiên cứu của chúng tôi kết quả ở bảng 4 thời gian phẫu thuật của nhóm 2 là $36.66 \pm$ 4.17 phút tương đương nhóm 1 là $38.96 \pm$ $6.75 p$ hút với $(p<0,05)$. Nhìn chung phương pháp TCI không gây ảnh hưởng một cách khác biệt đến quy trình làm phẫu thuât so với phương pháp gây mê đơn thuần. Nguyễn Thị Quý (2015) [5] nghiên cứu hiệu quả vô cảm của bệnh nhân TCI propofol kiểm soát nồng độ đích cho nội soi tán sỏi niệu quản ngược dòng ở bệnh nhân ngoại trú ở nhóm TCI có thời gian làm thủ thuật là $25,8 \pm 17,4$ phút tương đương nhóm gây mê là $24,8 \pm 16,1$ phút. Kết quả này cũng phù hợp với kết quả nghiên cứu của chúng tôi.

\subsection{Vê mức độ hài lòng của phẫu thuâtt} viên theo VAS. Kết quả ở bảng 5 cho thấy mức độ hài lòng của phẫu thuât viên được tiến hành khảo sát ngay sau khi phấu thuật. Nhóm 2 có tỷ lệ mức rất hài lòng là $33,33 \%$ và hài lòng là $66,67 \%$ cao hơn có ý nghĩa thống kê so với nhóm 1 có tỷ lệ mức rất hài lòng là $6,70 \%$ và hài lòng là $93,30 \%$ với $(p<0,05)$. Ớ các mức: không hài lòng, hài lòng ít, hài lòng vừa không có trong hai nhóm nghiên cứu.

Nguyễn Quang Bình nghiên cứu TCI bằng propofol ở bệnh nhân tháo nẹp vít xương gò má cho thây mức độ rất hài long ở nhóm TCI là $36,35 \%$ và nhóm gây mê là $6,09 \%(p<0,05)$. Kết quả này cũng phù hợp với kết quả nghiên cứu của chúng tôi [4].

Tóm lại: các số liệu nghiên cứu sử dụng TCI cho bệnh nhân nhổ rằng khôn cho thấy, số bệnh nhân cử động cản trở phẫu thuật, mức độ khó của phẫu thuật răng khôn hàm dưới theo pedersen, thời gian phẫu thuật tương đương nhóm gây mê. Mức độ rất hài lòng của phẫu thuật viên ở nhóm TCI cao hơn nhóm GM.

\section{KẾT LUÂNN}

Dưới tác dụng an thân của propofol nhóm TCI có mức độ thuận lợi cho quá trình phẫu thuật tương đương nhóm gây mê trong phẫu thuật nhổ răng khôn.

TÀI LIỆU THAM KHẢO

1. Sơn, Đ.T (2000), "Nhận xét về lực cản và các biện 
pháp giải quyết trong phẫu thuật răng khôn hàm dưới khó, in Hoc viên Quân Y. 2000.

2. Hưng, M.Đ (1996), Bảng chỉ số khó nhổ răng khôn hàm dưới lệch chìm. Tập san Răng Hàm Mặt, 1996: p. 23-25

3. Bình, N.Q (2012), "Nghiên cứu phương pháp an thân bằng propofol do bênh nhân tự điều khiển trong phẫu thuật răng", Khoa Gây mê - Hồi sức. 2012. Viên Trung ương Quân đôi 108. p. 20 - 26.

4. Bình, N.Q (2018), "Nghiên cứu phương pháp an thần theo nồng độ đích bằng propofol trong phẫu thuât lấy nep vít xương vùng hàm măt". Khoa gây mê-hồi sức viện răng hàm mặt Trung ương. 2018: Hà Nội. p. 10.

5. Quý, N.T. and N.Q. Kính (2015). "Đánh giá hiêu quả vô cảm và tính an toàn của gây mê propofol kiểm soát nồng độ đích cho nội soi tán sỏi niêu quản ngược dông ở bệnh nhân ngoại trú". Viện nghiên cứu khoa học $Y$ dược lâm sàng 108. 2015: Hà Nội. p. 66.

\title{
THƯC TRANG KHẨU PHẦN BŨ̃A ĂN CA CÔNG NHÂN DÊTT MAY MộT SỐ ĐIỂM MIỀN BẮC
}

\author{
Nguyễn Thị Lan Hương ${ }^{1}$, Đỗ Thị Phương Hà², \\ Lê Bạch Mai ${ }^{2}$, Đố Trần Hải ${ }^{3}$
}

\section{TÓM TẮT}

Nghiên cứu mô tả cắt ngang được thực hiện trên 959 công nhân tại 12 công ty Dệt may thuộc 5 tỉnh phía Bắc nhằm đánh giá thực trang khẩu phần bữa ăn ca công nhân dệt may. Kết quá cho thây thực phẩm được tiêu thụ trung bình cao nhất trong khẩu phân ăn ca công nhẩn là nhóm ngũ cốc $(151,2 \mathrm{~g})$, kế đến là nhóm rau quả $(65,4 \mathrm{~g})$, thit và cá $(58,2 \mathrm{~g})$. Nhóm trứng, sữa, bánh kẹo ngọt, đồ uống có cồn được tiêu thu rất ít. Trung bình năng lương trong khẩu phần ăn thực tế cung cấp là 745,6 kcal đáp ứng 83,9\% năng lướng theo NCDDKN với tỷ lê Protein: Lipid: Glucid là 15,2: 21,7: 61,3. Tỷ lệ $\mathrm{Ca} / \mathrm{P}$; lượng vitamin $\mathrm{B} 2$, $\mathrm{PP}$ và canxi, sắt, kẽm của cả suất ăn cung cấp và khấu phần thực tế của công nhân cơ bản đều chưa đáp ứng đủ theo nhu cầu khuyến nghi, thể hiên sư thiếu cân đối về hàm lượng vitamin, khoáng chất trong khẩu phần ăn.

Tư khóa: bữa ăn ca, khẩu phần, dinh dưỡng, công ty dệt may.

\section{SUMMARY \\ WORKER 'S MEAL AT SOME GARMENT COMPANIES OF THE NORTH REGION IN VIET NAM}

A cross-sectional survey was carried out among the randomly selected 959 workers from 12 different garment companies in 5 provinces located at the North region in Viet Nam by weight measure and take note method to assess lunch diets of garment workers. The actual diets of workers showed that the highest average food consumption was the cereals $(151,2 \mathrm{~g})$, vegetable and fruits $(65,4 \mathrm{~g})$, meat and fish

${ }^{1}$ Bênh viên đa khoa tỉnh Phú Thọ

2 Viện Dinh dướng Quốc gia

${ }^{3}$ Viên Khoa hoc An toàn và Vê sinh lao động

Chiu trách nhiệm chính: Nguyễn Thị Lan Hương

Email: lanhuong387@gmail.com

Ngày nhận bài: 21.10 .2020

Ngày phản biên khoa hoc: 27.11.2020

Ngày duyệt bài: 9.12 .2020
$(58,2 \mathrm{~g})$. Eggs, milk, sweets, and alcoholic drinks are consumed very little. The average energy in the diet actually provided was $745.6 \mathrm{kcal}$ to meet $83,9 \%$ the recommended dietary allowance (RDA) with Protein: Lipid: Glucid ratio of $15,2: 21,7: 61,3$. The ratio of $\mathrm{Ca} / \mathrm{P}$, viatmin $\mathrm{B} 2, \mathrm{PP}$, calcium, iron and zinc of lunch meal were not enough to meet the RDA, reflecting the imbalance in content of vitamins and minerals in the worker's diet.

Key words: worker's meal, dietary, nutrition, garment company

\section{I. ĐĂT VẤN ĐỀ}

Hiện nay các số liệu về thực trạng khẩu phần và chất lượng dinh dưỡng bữa ăn ca của công nhân còn rất ít, chủ yếu tập trung vào năng lượng khẩu phần, các giá trị dinh dưỡng khẩu phần chưa được nghiên cứu cụ thể. Bên cạnh đó, khảo sát chỉ mang tính nhỏ lẻ ở môt vài cơ sở sản xuất và không mang tính đại diện. Thực tế cho thấý, bữa ăn thiếu hoặc thừa dinh dưỡng đều không tốt mà cần đủ và cân đối về các chất dinh dưỡng, đăcc biệt đối với người lao động.

Theo nghiển cứu mới của Văn phòng Lao động Quốc tế thì chế độ ăn uống nghèo nàn trong công việc đang khiến các nước trên thế giới mất tới $20 \%$ năng suất lao động do suy dinh dương hoăc tình trang thừa cân và béo phì gây ra cho 1 tỷ người ở các nước đang phát triển hay các nền kinh tế công nghiệp hóa [1].

Theo đánh giá của Viện Dinh dưỡng Quốc gia, bữa ăn của công nhân tại môt số Khu công nghiệp phần lớn là mất cân đối. Khẩu phần ăn cả ngày của công nhân chỉ đáp ứng khoảng $90 \%$ nhu cầu dinh dưỡng cho nam và $70 \%$ nhu cầu cho nữ [2]. Ngành dệt may là một trong những ngành mũi nhọn của Việt Nam, ngành có kim ngạch xuất khẩu lớn thứ hai với giá trị xuất khẩu đóng góp từ $10-15 \%$ vào GDP, chỉ sau linh kiện 